\title{
High-Accuracy Distance Measurement Between Remote Methyls in Specifically Protonated Proteins.
}

\author{
Remy Sounier, ${ }^{\S}$ Laurence Blanchard,${ }^{\S}$ Zhengrong Wu, ${ }^{\ddagger}$ Jérôme Boisbouvier ${ }^{\star \S}$ \\ ${ }^{\S}$ IBS, Institut de Biologie Structurale Jean-Pierre Ebel, 41 rue Jules Horowitz, F-38027 Grenoble; CEA; CNRS; Université \\ Joseph Fourier. ${ }^{\ddagger}$ Biochemistry Department; Ohio State University, Columbus, Ohio 43210, USA.
}

Supporting Information S1 : Preparation of Ile- $\delta_{1}$ specifically protonated proteins.

- Cost-effective production of the specifically protonated isoleucine precursor :

Methylene protons at position 3 of 2-ketobutyrate or 2-keto-4- ${ }^{13} \mathrm{C}$-butyrate were exchanged with deuterium by base catalysis. ${ }^{1} 50 \mathrm{mg}$ of ketobutyrate were diluted in $150 \mathrm{~mL}$ of $99.9 \%{ }^{2} \mathrm{H}_{2} \mathrm{O}$. pH was initially raised to 10.5 by the addition of $40 \%$ sodium deuteroxide (NaOD) and incubated at $40^{\circ} \mathrm{C}$ for 90 hours. Completion of the H/D exchange was monitored by ${ }^{1} \mathrm{H}$ NMR spectroscopy. The $\mathrm{pH}$ was then decreased to 7.2 by the addition of acid chloride deuterium (DCl). The $\mathrm{D}_{2} \mathrm{O}$ used for the exchange was recycled in bacteria growth medium as indicated below.

- Production of $\left[\mathrm{CH}_{3}\right]-$ Ile- $\delta_{1}$-proteins

E. coli BL21(DE3) cells were transformed with a plasmid carrying the human ubiquitin gene. Bacteria were grown in stages to adapt them to $99.9 \% \mathrm{D}_{2} \mathrm{O}$ and glucose- $\mathrm{d}_{7}$. In the final stage of this protocol, bacteria were grown at $37^{\circ} \mathrm{C}$ in $350 \mathrm{~mL}$ minimal $\mathrm{M} 9$ media containing $1 \mathrm{~g} / \mathrm{L}{ }^{15} \mathrm{ND}_{4} \mathrm{Cl}, 2 \mathrm{~g} / \mathrm{L}$ D-glucose- $\mathrm{d}_{7}$, and $99.9 \% \mathrm{D}_{2} \mathrm{O}$. When the O.D. $(600 \mathrm{~nm})$ reached 0.8 , a 150 $\mathrm{mL}$ solution containing $330 \mathrm{mg} / \mathrm{L}$ of 2-keto-3,3- $\mathrm{d}_{2}$-butyrate (prepared as described above), $1 \mathrm{~g} / \mathrm{L}$ ${ }^{15} \mathrm{ND}_{4} \mathrm{Cl}, 2 \mathrm{~g} / \mathrm{L}$ D-glucose- $\mathrm{d}_{7}$ was added. After $1 \mathrm{~h}$, protein expression was induced by the addition of IPTG to a final concentration of $0.5 \mathrm{mM}$. The cells were then grown at $37^{\circ} \mathrm{C}$ during 12 hours before harvesting. Ubiquitin was purified by chromatography using an anion exchange column (Q-Sepharose, Amersham Pharmacia Biotech) and a gel filtration column (Superdex-75, Amersham Pharmacia Biotech). Final yield was $61 \mathrm{mg} / \mathrm{L}$ of $\mathrm{U}-\left[{ }^{15} \mathrm{~N}\right], \mathrm{U}-\left[{ }^{2} \mathrm{H}\right],\left[{ }^{12} \mathrm{C}^{1} \mathrm{H}_{3}\right]-\mathrm{Ile}-\delta_{1}$ purified ubiquitin. The final NMR sample consisted of $1 \mathrm{mM}$ of ubiquitin, $10 \mathrm{mM}$ of MES ( $\mathrm{pH}=7.4$ uncorrected) dissolved in $400 \mu \mathrm{L} \mathrm{D}_{2} \mathrm{O}$.

$\mathrm{U}-\left[{ }^{[5} \mathrm{N}\right], \mathrm{U}-\left[{ }^{2} \mathrm{H}\right], \mathrm{U}-\left[{ }^{13} \mathrm{C}\right],\left[{ }^{12} \mathrm{C}^{1} \mathrm{H}_{3}\right]-\mathrm{Ile}-\delta_{1}$ and U- $\left[{ }^{15} \mathrm{~N}\right], \mathrm{U}-\left[{ }^{2} \mathrm{H}\right],\left[{ }^{13} \mathrm{C}^{1} \mathrm{H}_{3}\right]-\mathrm{Ile}-\delta_{1}$-ubiquitin samples were produced similarly by using D-glucose- ${ }^{13} \mathrm{C}_{6}-\mathrm{d}_{7}$ or 2 -keto-3,3- $\mathrm{d}_{2}-4-{ }^{13} \mathrm{C}$-butyrate respectively in the final stage of overexpression.

$\mathrm{U}-\left[{ }^{2} \mathrm{H}\right],\left[{ }^{12} \mathrm{C}^{1} \mathrm{H}_{3}\right]-\mathrm{Ile}-\delta_{1} \gamma \mathrm{S}$-crystallin sample was prepared as described by $\mathrm{Wu}$ et al. $(2005)^{2}$ with $\mathrm{ND}_{4} \mathrm{Cl}, \mathrm{D}_{2} \mathrm{O}, \mathrm{D}$-glucose- $\mathrm{d}_{7}$ and 2-keto-3,3- $\mathrm{d}_{2}$-butyrate as unique carbon and hydrogen sources.

- Specific methyl labeling and perdeuteration efficiency

The level of deuterium incorporation into ubiquitin was quantified by ${ }^{1} \mathrm{H}$ NMR. Only seven intense signals from 0.3 to $0.9 \mathrm{ppm}$ corresponding to the Ile- $\delta_{1}$ methyls were visible in ${ }^{1} \mathrm{H}$ NMR spectra of $\mathrm{U}-\left[{ }^{15} \mathrm{~N}\right], \mathrm{U}-\left[{ }^{2} \mathrm{H}\right],\left[{ }^{12} \mathrm{C}^{1} \mathrm{H}_{3}\right]-\mathrm{Ile}-\delta_{1}$ ubiquitin sample (figure $\mathrm{S} 1(\mathrm{~B})$ ). Quantitative analysis of intensities of residual signals for other aliphatic protons and comparison with spectra of protonated ubiquitin (figure S1(A)) revealed that the deuteration level was $98.5 \%$.

No signals for Ile- $\delta_{1}$ carbons were observed in directly detected $1 \mathrm{D}^{13} \mathrm{C}$ NMR spectra of $\mathrm{U}-\left[{ }^{15} \mathrm{~N}\right], \mathrm{U}-\left[{ }^{2} \mathrm{H}\right], \mathrm{U}-\left[{ }^{13} \mathrm{C}\right],\left[{ }^{12} \mathrm{C}^{1} \mathrm{H}_{3}\right]-\mathrm{Ile}-\delta_{1}$ ubiquitin sample (figure $\mathrm{S} 1(\mathrm{D})$ ). Comparison with ${ }^{13} \mathrm{C}$ spectra recorded on $\mathrm{U}-\left[{ }^{15} \mathrm{~N}\right], \mathrm{U}-\left[{ }^{13} \mathrm{C}\right]$ ubiquitin (figure $\mathrm{S} 1(\mathrm{C})$ ) indicated that the incorporation of 
methyl from ketobutyrate precursor is larger than $98 \%$. Only signals of Ile- $\delta_{1}$ carbons were observed in ${ }^{13} \mathrm{C}$ spectra recorded on $\mathrm{U}-\left[{ }^{15} \mathrm{~N}\right]$, U- $\left[{ }^{2} \mathrm{H}\right],\left[{ }^{13} \mathrm{C}^{1} \mathrm{H}_{3}\right]-\mathrm{Ile}-\delta_{1}$ ubiquitin sample (figure $\mathrm{S} 1(\mathrm{E})$ ), indicating that ${ }^{13} \mathrm{C}^{1} \mathrm{H}_{3}$ of ketobutyrate was not incorporated in methyls different from Ile$\delta_{1}$.
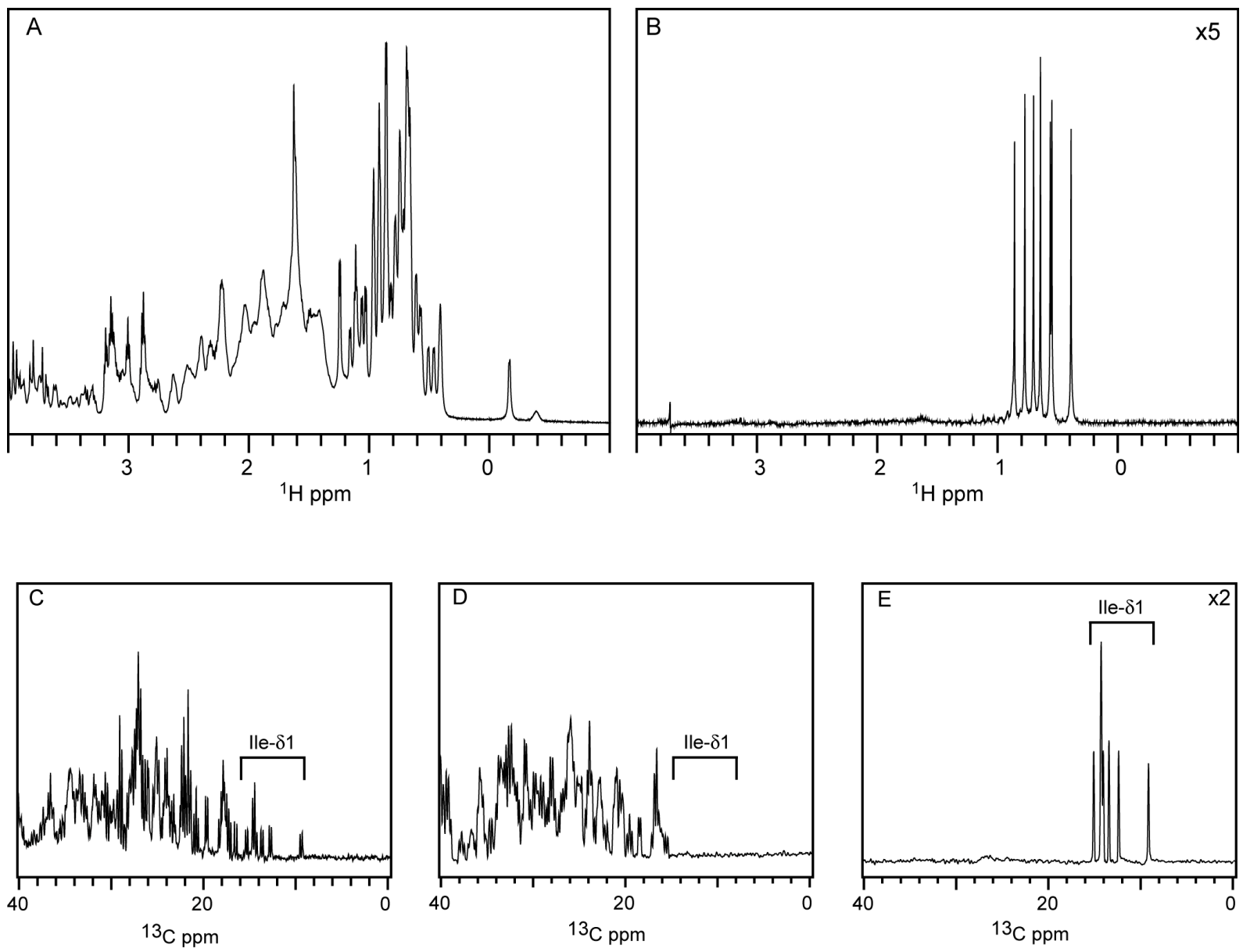

Figure S1. ${ }^{1} \mathrm{H}$ NMR spectra of $\mathrm{U}-\left[{ }^{15} \mathrm{~N}\right]$ ubiquitin $(\mathrm{A})$ and $\mathrm{U}-\left[{ }^{15} \mathrm{~N}\right], \mathrm{U}-\left[{ }^{2} \mathrm{H}\right],\left[{ }^{12} \mathrm{C}^{1} \mathrm{H}_{3}\right]-\mathrm{Ile}-\mathrm{\delta}_{1}(\mathrm{~B})$. Compared with (A) the vertical scale has been multiplied by a factor 5 in (B). ${ }^{1} \mathrm{H}$ decoupled ${ }^{13} \mathrm{C}-\mathrm{NMR}$ spectra of $\mathrm{U}-\left[{ }^{15} \mathrm{~N}\right], \mathrm{U}-\left[{ }^{13} \mathrm{C}\right]$ ubiquitin $(\mathrm{C}), \mathrm{U}-\left[{ }^{15} \mathrm{~N}\right], \mathrm{U}-\left[{ }^{2} \mathrm{H}\right]$, $\mathrm{U}-\left[{ }^{13} \mathrm{C}\right],\left[{ }^{12} \mathrm{C}^{1} \mathrm{H}_{3}\right]-\mathrm{Ile}-\delta_{1}$ ubiquitin (D) and U- $\left[{ }^{15} \mathrm{~N}\right], \mathrm{U}-\left[{ }^{2} \mathrm{H}\right],\left[{ }^{13} \mathrm{C}^{1} \mathrm{H}_{3}\right]-$ Ile- $\delta_{1}$ ubiquitin (E). Compared with (C) and (D) the vertical scale has been multiplied by a factor 2 in $(\mathrm{E})$. 
Supporting Information S2 : Detection of NOEs between remote protons in methyl specific protonated proteins.

For the observation of weak NOEs between specifically protonated methyl groups, in deuterated samples, particular caution should be paid on residual protons. Even at a deuteration level as high as $98 \%$, a methyl, with residual protonation level of $2 \%$ and separated by $5 \AA$ from a fully protonated Ile- $\delta_{1}$ methyl, gives rise to a NOE cross-peak more intense than a NOE crosspeak between two fully protonated Ile- $\delta_{1}$ methyls separated by more than $10 \AA$. As each Ile- $\delta_{1}$ methyl is surrounded on average by 7 other methyl groups distant by less than $5 \AA$, particular attention should be paid to the analysis of NOE between distant methyls.

As the structure and full assignment are known for both ubiquitin ${ }^{3}$ and $\gamma \mathrm{S}$-crystallin ${ }^{2}$, we were able to verify if such "spurious NOEs" overlap with cross-peaks between two Ile- $\delta_{1}$ methyls. For $\gamma$ S-crystallin, no spurious NOEs overlapped with observed inter Ile- $\delta_{1}$ methyls NOE, validating the assignment of these NOEs. The quantitative analysis of NOEs for $\gamma \mathrm{S}$-crystallin was performed with standard NOESY experiments recorded on $\mathrm{U}-\left[{ }^{2} \mathrm{H}\right],\left[{ }^{12} \mathrm{C}^{1} \mathrm{H}_{3}\right]-\mathrm{Ile}-\delta_{1} \gamma \mathrm{S}$-crystallin sample.

For ubiquitin several of these spurious NOEs were predicted to overlap with Ile- $\delta_{1}$ intermethyl NOEs. To suppress these artefacts, we have developed a general approach based on the use of ${ }^{12} \mathrm{C}$-filtered NOESY experiments ${ }^{4}$ (Figure S2) in combination with the use of $\mathrm{U}-\left[{ }^{15} \mathrm{~N}\right]$, $\mathrm{U}-\left[{ }^{2} \mathrm{H}\right], \mathrm{U}-\left[{ }^{13} \mathrm{C}\right],\left[{ }^{12} \mathrm{C}^{1} \mathrm{H}_{3}\right]-$ Ile- $\delta_{1}$ ubiquitin sample. Alternatively ${ }^{13} \mathrm{C}$-filtered NOESY or $4 \mathrm{D}{ }^{13} \mathrm{C}$ edited NOESY experiments ${ }^{5}$ in combination with a U- $\left[{ }^{15} \mathrm{~N}\right], \mathrm{U}-\left[{ }^{2} \mathrm{H}\right],\left[{ }^{13} \mathrm{C}^{1} \mathrm{H}_{3}\right]-\mathrm{Ile}-\delta_{1}$ sample can be used to filter out these spurious NOEs. The first labeling scheme is more suitable for longdistance NOE observation as methyl proton relaxation will not be affected by ${ }^{13} \mathrm{C}-{ }^{1} \mathrm{H}$ dipolar interaction. It also does not require ${ }^{13} \mathrm{C}$-specific labeled ketobutyrate. For large proteins, the second labeling scheme allows to use 3D or 4D ${ }^{13} \mathrm{C}$-edited NOESY experiments in case of overlap in 2D NOESY spectra.

The efficiency of the ${ }^{12} \mathrm{C}$-filtered NOESY experiment to eliminate spurious NOEs was demonstrated for ubiquitin (Figure S3). The NOE quantitative analysis for ubiquitin was realized on the basis of ${ }^{12} \mathrm{C}$-filtered NOESY experiments (Figure S2) recorded on U- $\left[{ }^{15} \mathrm{~N}\right], \mathrm{U}-\left[{ }^{2} \mathrm{H}\right]$, U$\left[{ }^{13} \mathrm{C}\right],\left[{ }^{12} \mathrm{C}^{1} \mathrm{H}_{3}\right]-$ Ile- $\delta_{1}$ ubiquitin sample. 


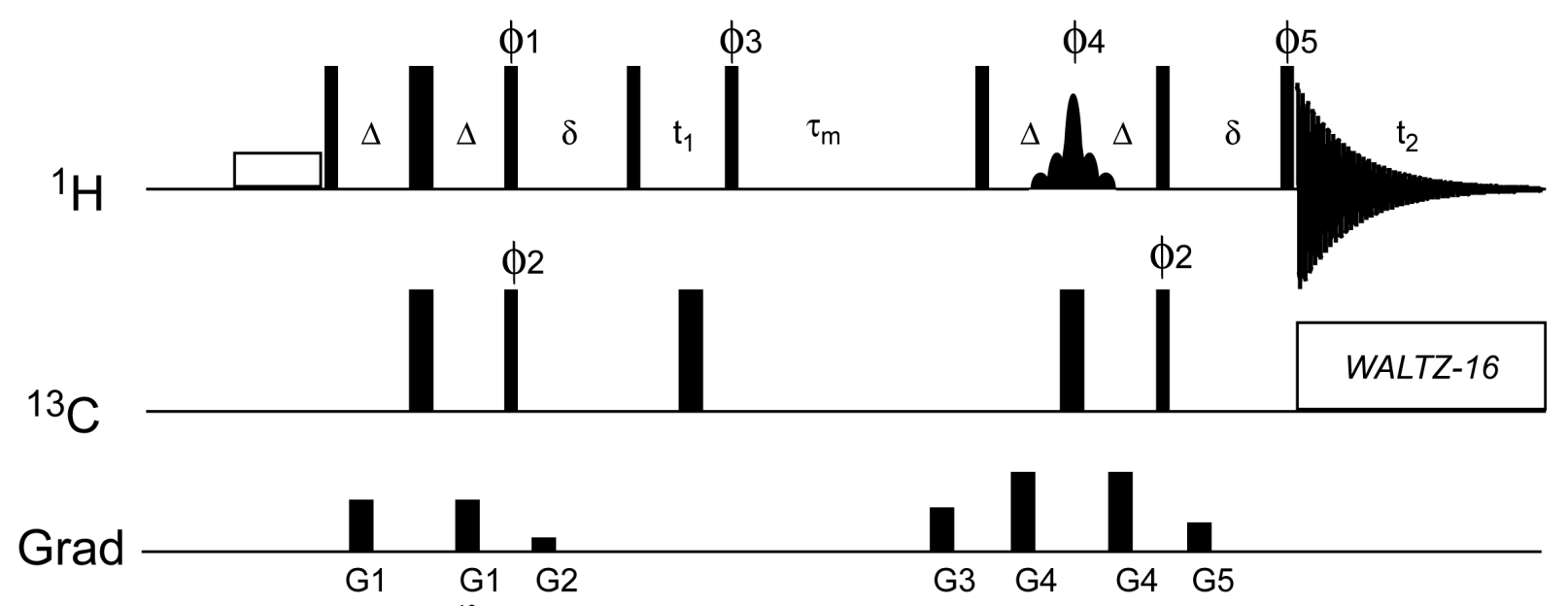

Figure S2. Pulse scheme of the ${ }^{12} \mathrm{C}$-filtered 2D NOESY experiment. Narrow and wide rectangular pulses are applied with flip angles of $90^{\circ}$ and $180^{\circ}$, respectively. Unless specified, pulses are applied along the $\mathrm{x}$-axis. The ${ }^{1} \mathrm{H}$ frequencies are positioned at the center of the Ile- $\delta 1$ methyl region and the ${ }^{13} \mathrm{C}$ frequencies are positioned at the center of the Ile- $\mathrm{C}_{\beta}$. The shaped ${ }^{1} \mathrm{H}$ pulse is of the $180^{\circ}$ REBURP type (3 ms duration at $800 \mathrm{MHz}$, for a $1600 \mathrm{~Hz}$ inversion bandwidth, centered in the Ile- $\delta 1$ methyl region). Weak presaturation of the residual HDO resonance is used between scans. The durations and strengths of the z-gradients in units of $(\mathrm{ms} ; \mathrm{G} / \mathrm{cm})$ are: $\mathrm{G} 1=(0.2 ; 26), \mathrm{G} 2=$ $(1 ; 6), \mathrm{G} 3=(1 ; 22), \mathrm{G} 4=(0.2 ; 58), \mathrm{G} 5=(1 ; 14)$. The phase cycle is: $\phi_{1}=4(\mathrm{x}), 4(-\mathrm{x}) ; \phi_{2}=\mathrm{x},-\mathrm{x}, \mathrm{x}, \mathrm{x},-\mathrm{x}, \mathrm{x},-\mathrm{x},-\mathrm{x}, \mathrm{x},-$ $\mathrm{x}, \mathrm{x}, \mathrm{x},-\mathrm{x}, \mathrm{x},-\mathrm{x},-\mathrm{x} ; \phi_{3}=8(\mathrm{x}) ; 8(-\mathrm{x}) ; \phi_{4}=2(\mathrm{x}), 2(\mathrm{y}) ; \phi_{5}=\mathrm{x},-\mathrm{x}$; rec $=\mathrm{x},-\mathrm{x},-\mathrm{x}, \mathrm{x},-\mathrm{x}, \mathrm{x}, \mathrm{x},-\mathrm{x},-\mathrm{x}, \mathrm{x}, \mathrm{x},-\mathrm{x}, \mathrm{x},-\mathrm{x},-\mathrm{x}, \mathrm{x}$. Quadrature detection in $\mathrm{t}_{1}$ is achieved by incrementing $\phi_{3}$ in the usual States-TPPI manner. The gradient recovery delays have been set to $\delta=1 \mathrm{~ms}$, and the transfer delay $\Delta=2 \mathrm{~ms}$. For optimal sensitivity, the interscan delay $\mathrm{d}_{1}$ has to be set to $\mathrm{d}_{1} \sim 1.2 \mathrm{xT}_{1}$, where $\mathrm{T}_{1}$ is the average methyl proton longitudinal relaxation time (i.e. $1.5 \mathrm{~s}$ for $\mathrm{U}-\left[{ }^{15} \mathrm{~N}\right]$, U- $\left[{ }^{2} \mathrm{H}\right]$, $\mathrm{U}-\left[{ }^{13} \mathrm{C}\right],\left[{ }^{12} \mathrm{C}^{1} \mathrm{H}_{3}\right]-$ Ile- $\delta_{1}$-ubiquitin sample and $1.0 \mathrm{~s}$ for $\mathrm{U}-\left[{ }^{2} \mathrm{H}\right],\left[{ }^{12} \mathrm{C}^{1} \mathrm{H}_{3}\right]-$ Ile- $\delta_{1}-\gamma \mathrm{S}$-crystallin sample).
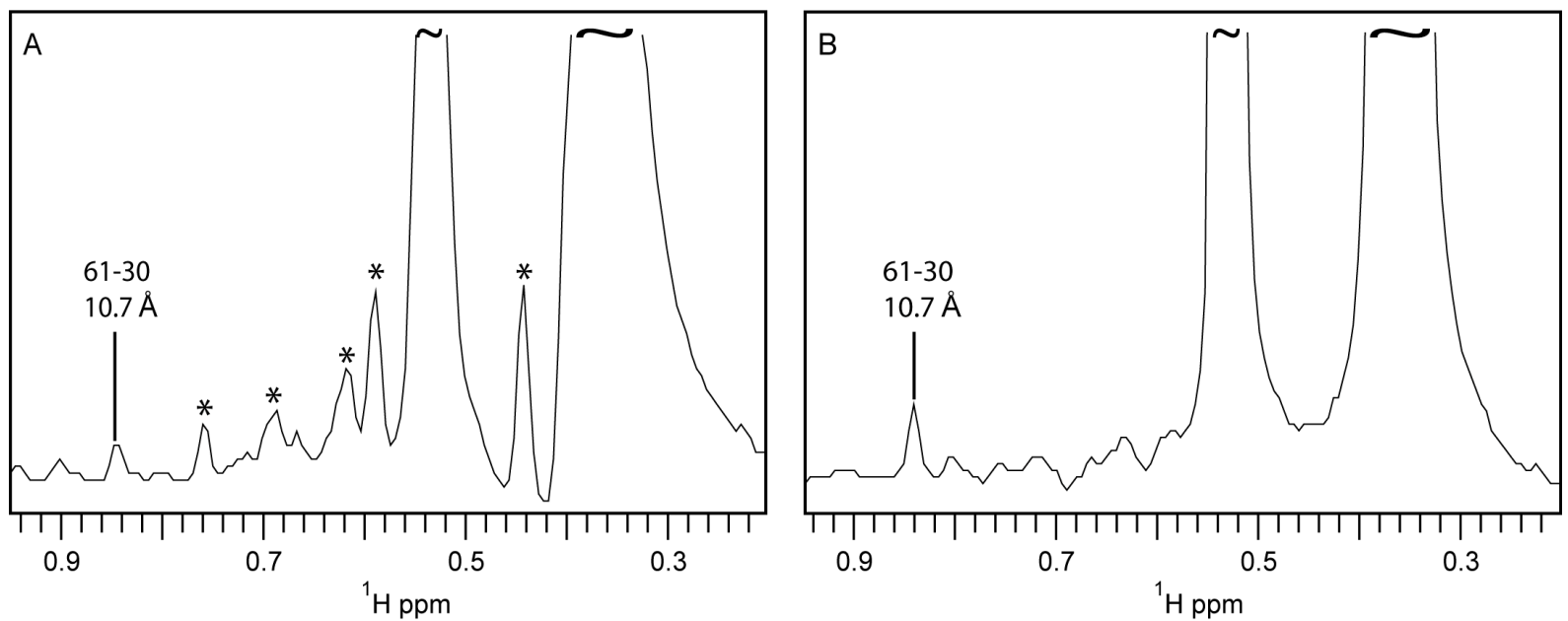

Figure S3. Suppression of spurious NOEs. $F_{2}$ cross-sections at $\delta_{1}$ methyl frequency of ubiquitin Ile 61 is displayed. The $800 \mathrm{MHz}$ NOESY spectra were acquired in 14 hours with pulse-scheme of Figure $\mathrm{S} 2$ on a $1 \mathrm{mM} \mathrm{U}-\left[{ }^{15} \mathrm{~N}\right]$, U- $\left[{ }^{2} \mathrm{H}\right]$, $\left[{ }^{12} \mathrm{C}^{1} \mathrm{H}_{3}\right]$-Ile- $\delta_{1}$-ubiquitin sample (spectra A) or on a $1 \mathrm{mM} \mathrm{U}-\left[{ }^{15} \mathrm{~N}\right], \mathrm{U}-\left[{ }^{2} \mathrm{H}\right], \mathrm{U}-\left[{ }^{13} \mathrm{C}\right],\left[{ }^{12} \mathrm{C}^{1} \mathrm{H}_{3}\right]-\mathrm{Ile}-\delta_{1}$-ubiquitin sample (spectrum B). In (A) spurious NOE peaks have been labeled with a star. 
Supporting Information S3 : Full relaxation matrix analysis of NOEs between remote protons in methyl-specific protonated proteins.

-Quantification of intermethyl distances :

In order to account for spin diffusion effects, a full-relaxation matrix approach was employed. The NOE volumes between proton pairs can be described by Bloch equations : ${ }^{6-9}$

$$
\frac{d}{d t_{m}} V\left(t_{m}\right)=-\sigma \cdot V\left(t_{m}\right)
$$

where $\mathrm{V}\left(\mathrm{t}_{\mathrm{m}}\right)$ is the matrix of peak volumes extracted from NOESY spectra recorded with mixing time $t_{m}$, and $\sigma$ is the relaxation matrix. Integration of the Bloch equation can then be performed analytically in order to obtain the volume matrix at mixing time $\mathrm{t}_{\mathrm{m}}$ :

$$
V\left(t_{m}\right)=\exp \left(-\sigma \cdot t_{m}\right) V(0)
$$

Experimentally, $\mathrm{V}\left(\mathrm{t}_{\mathrm{m}}\right)$ and $\mathrm{V}(0)$ were measured, and $\sigma$ was unknown. Given the resolution of the spectra and the simplicity of the spin system in Ile- $\delta_{1}$ methyl specific protonated samples, the relaxation matrix $\sigma$ was directly determined from peak volumes in NOESY spectra. Equation (2) can be rearranged to give $\sigma$ in terms of $\mathrm{V}\left(\mathrm{t}_{\mathrm{m}}\right)$ and $\mathrm{V}(0)$ :

$$
\sigma=-\left(\ln \left[V\left(t_{m}\right) \cdot V(0)^{-1}\right]\right) / t_{m}
$$

For simplicity reasons equation (3) was most easily solved by rewriting it in terms of the matrix of eigenvectors, $[\mathrm{X}]$, and the diagonal matrix of eigenvalues, $[\mathrm{D}]$, of $\mathrm{V}\left(\mathrm{t}_{\mathrm{m}}\right) \cdot \mathrm{V}(0)^{-1}$ :

$$
\sigma=-\left([X](\ln [D])[X]^{-1}\right) / t_{m}
$$

Obtaining the relaxation matrix $\sigma$ from $\mathrm{V}\left(\mathrm{t}_{\mathrm{m}}\right)$ and $\mathrm{V}(0)$ was thus a simple problem of matrix algebra. The inter-methyl distance matrix was then extracted from the off diagonal terms of $\sigma$. In the limit of an inter-methyl distance between methyl A and B being large compared to the intramethyl proton-proton distance $(1.8 \AA)$ and neglecting all sources of internal dynamics except fast methyl rotation, ${ }^{10}$ the average intermethyl distance $\left\langle\mathrm{r}_{\mathrm{AB}}{ }^{3}\right\rangle$ can be extracted from :

$$
\sigma_{A B} \cong \frac{3 \tau_{C}}{10}\left(\frac{\mu_{0} \gamma_{H}^{2} h}{4 \pi\left\langle r_{A B}^{3}\right\rangle}\right)^{2}\left(\frac{6}{1+\left(2 \omega \tau_{C}\right)^{2}}-1\right)
$$

where $\gamma_{\mathrm{H}}$ is the gyromagnetic ratio of proton, $\tau_{\mathrm{C}}$ is the overall tumbling time, and $\omega$ is the spectrometer frequency.

This approach was encoded in a Python program to calculate directly inter-methyl distances from the NOESY peak volumes files $\mathrm{V}\left(\mathrm{t}_{\mathrm{m}}\right)$ and $\mathrm{V}(0)$ generated by nmrPipe package. ${ }^{11}$ This program is available online (http://www.ibs.fr/ext/labos/LRMN/softs/welcome.htm).

- Evaluation of spin diffusion contribution :

The experimentally determined relaxation matrix was used to simulate NOESY peak volumes. To evaluate the contributions of spin diffusion to the volume of a NOE cross-peak between methyls $i$ and $\mathrm{j}$, the corresponding relaxation matrix element $\sigma_{\mathrm{ij}}$ was set to zero before computation of NOESY peak volumes. This has the effect of simulating only that portion of NOE observed due to indirect effects. 


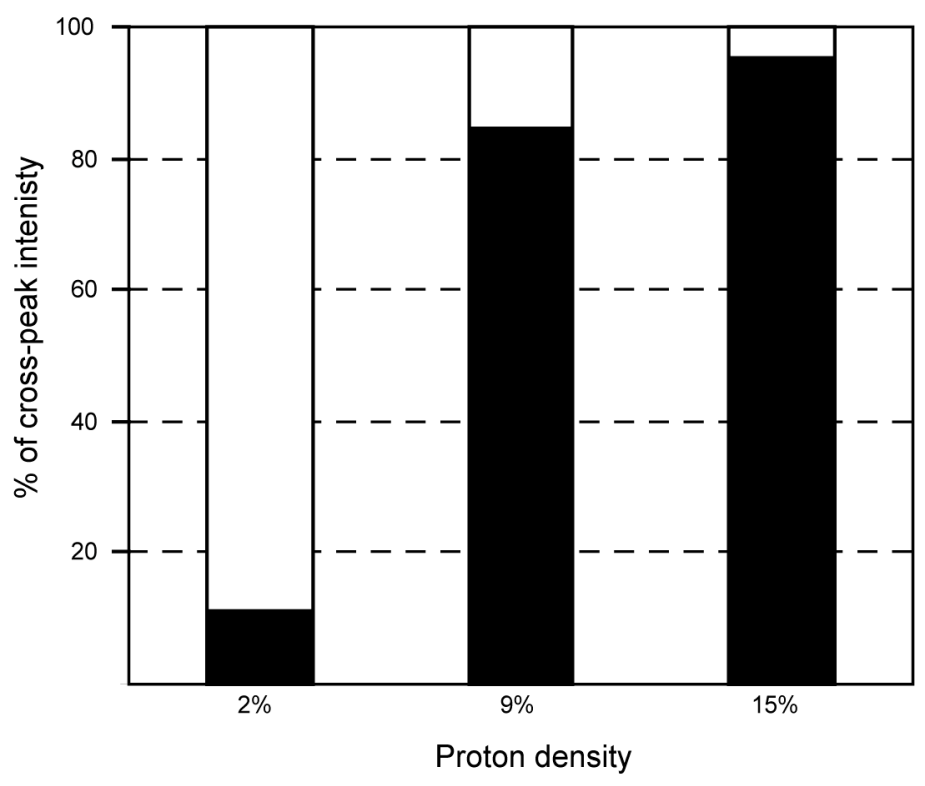

Figure S4. Evaluation of spin diffusion contribution to the NOE cross-peaks observed between Ile- $\delta 1$ methyls distant by more than $10 \AA$ in $\gamma \mathrm{S}$-crystallin. $2 \%$ of proton density corresponds to a $\mathrm{U}-\left[{ }^{2} \mathrm{H}\right],\left[\mathrm{CH}_{3}\right]-\mathrm{Ile}-\delta 1-\gamma \mathrm{S}$-crystallin. $9 \%$ of proton density corresponds to $\mathrm{U}-\left[{ }^{2} \mathrm{H}\right],\left[\mathrm{CH}_{3}\right]-\mathrm{Ile}-\delta 1$, $\left[\mathrm{CH}_{3}\right]-\mathrm{Leu},\left[\mathrm{CH}_{3}\right]-\mathrm{Val}-\gamma \mathrm{S}$-crystallin. $15 \%$ corresponds to the proton density in a $\gamma \mathrm{S}$-crystallin sample where all the methyls are protonated while the other sites remain deuterated. 


\section{References:}

(1) Gardner, K. H.; Kay, L. E. J. Am. Chem. Soc. 1997, 119, 7599-7600.

(2) (a) Grishaev, A.; Wu, J.; Trewhella, J.; Bax, A. J. Am. Chem. Soc. 2005, 127, 1662116628. (b) Wu, Z.; Delaglio, F.; Wyatt, K.; Wistow, G.; Bax, A. Protein Sci. 2005, 14, 3101-3114.

(3) (a) Weber, P. L.; Brown, S. C.; Mueller, L. Biochemistry 1987, 26, 7282-7290. (b) Cornilescu, G.; Marquardt, J. L.; Ottiger, M.; Bax, A. J. Am. Chem. Soc. 1998, 120, 68366837.

(4) Vuister, G. W.; Kim, S.-J.; Wu, C.; Bax, A. J. Am. Chem. Soc. 1994, 116, 9206-9210.

(5) Tugarinov, V.; Ollerenshaw, J. E.; Kay, L. E. J. Am. Chem. Soc. 2005, 127, 8214-8225.

(6) Macura, S.; Ernst, R. R. Mol. Phys. 1980, 41, 95-107.

(7) Suri, A. K.; Levy, R. M. J. Magn. Reson. 1995, 106, 24-31.

(8) Abrgham, A., The Principles of Nuclear Magnetism. ed.; Claredon Press: Oxford, England, 1961;

(9) Olejniczak, E. T.; Gampe, R. T. j.; Fesik, S. W. J. Magn. Reson. 1986, 67, 28-41.

(10) Tropp, J. J. Chem. Phys. 1980, 72, 6035-6043.

(11) Delaglio, F.; Grzesiek, S.; Vuister, G. W.; Zhu, G.; Pfeifer, J.; Bax, A. J. Biomol. NMR 1995, 6, 277-293. 